\title{
Research on the Dilemma and Countermeasures of the Customer Service Management of International Freight Forwarders under the New Normal Take Guangdong GW Company as an example
}

\author{
Ling Zhang ${ }^{1, \mathrm{a}}$, Yifang Zhan*2,b,Zixi Wang ${ }^{3, \mathrm{c}}$, Meiyan Xiao ${ }^{3, \mathrm{c}}$ \\ ${ }^{1}$ School of Management University of Science and Technology Macau, China \\ ${ }^{2}$ School of Management Xinhua College of Sun Yat-sen University Guangzhou, China \\ ${ }^{3}$ School of Management Xinhua College of Sun Yat-sen University Guangzhou, China
}

\begin{abstract}
In the context of the global epidemic that has lasted for many months, international trade has been declining, and China's economy has entered a new normal. The global international freight forwarding industry is becoming more and more competitive. Many small and medium-sized international freight forwarding companies are facing difficulties in survival. Risk of bankruptcy. This article takes the customer service management of Guangdong GW international freight forwarder as an example, analyzes the dilemma of international freight forwarder customer service management under the new normal, and proposes corresponding solutions, explores the path to improve customer service management, and enhances the core competition in the market force. Thus, in order to improve the quality of customer service of international freight forwarders, it is necessary to carry out effective management innovation from improving the professional level of customer service personnel, improving customer service management system and improving customer service performance management. This will serve as a reference for the small and medium international freight forwarding industry to enhance the company's core competitiveness.
\end{abstract}

\section{Introduction}

\subsection{Research background}

At present, China's international freight forwarding industry is still in a stage of low profitability, and its main business is still traditional transportation, warehousing and other businesses, lacking innovation capabilities. In the context of the global plague that has lasted for many months, the global economy has continued to decline, and the Chinese economy has entered a new normal. The global international freight forwarding industry is becoming more and more competitive. Many small and medium-sized international freight forwarding companies are facing survival difficulties and few are facing bankruptcy. This will pose a huge challenge to China's international freight forwarding industry. How can China's small and medium-sized international freight forwarding companies explore and develop their core competitiveness, and be able to buck the trend in the increasingly severe market competition, get rid of the survival dilemma, and explore a way to adapt to the new normal, survive and develop, and improve the company's The core competitiveness is the urgent and primary problem that
China International Freight Forwarding Corporation has to solve. This article will analyze the dilemma of the service management of Guangdong GW international freight forwarding company, and propose corresponding solutions. The purpose is to enhance the company's core competitiveness in sustainable development, quickly get rid of the dilemma of survival, and play a certain reference role for the same industry.

\subsection{Theory Summary}

Service management is the first driving force for customers to perceive service quality as the business management. The International Federation of Freight Forwarders Association (FIATA) defines its regulations as: International freight forwarders are persons who collect transportation for the benefit of customers according to the instructions of customers, and are not carriers themselves. International freight forwarders can also engage in activities related to the delivery contract based on these conditions, such as storage (including storage), customs declaration, acceptance, and payment collection.

Zou Qijun (2019) researched that the work of crossborder e-commerce customer service is a window through which customers can understand the characteristics and

\footnotetext{
a605574968@qq.com

b*15013027271@139.com

caxaqwzx@163.com
} 
functions of the products sold in the store, and obtain more complete answers, faster feedback and better services [1]. Li Yongjian (2019) researched that the upgrading of customer service quality in the electric power industry is a fundamental element for the company to follow the development of the times. Therefore, the company must design more reasonable and scientific internal service procedures, pay attention to customer service management issues, and gradually improve the service level [2]. Scholar Xie Hongwu (2013) believes that through the establishment of a customer service management system, a company can form a computer information management system that provides customers with scientific service management [3]. Scholar Wang Xiqiang (2016) proposed that the development of China's small and medium freight forwarding companies should work hard in improving service content, improving after-sales service, and providing careful planning [4]. Li Jianying (2014) believes that the focus of the operation and management of freight forwarding companies has changed from traditional internal business growth to how to use and tap external customer resources [5]. Burnson and Patrick (2012) discussed the views of shippers and their international freight forwarders on basic brokerage and freight services. Shippers are minimizing their dependence on mature economies [6].

By comparing the above literature on the customer service management research of international freight forwarding companies, it is found that scholars have focused on doing a good job in product display, internal service procedures, information systems, after-sales service, and service awareness. There are fewer scholars in management research. This paper takes Guangdong GW Company in Guangdong Province as an example, from the perspective of the company's customer service management, studies the dilemma of Guangdong GW Company's customer service management, analyzes the reasons for the dilemma, and proposes countermeasures to solve the dilemma of customer service management and improve GW's core competitiveness. This is the innovative point of this article.

\section{Guangdong GW company profile}

Since its establishment in Guangzhou, Guangdong GW Company has provided comprehensive solutions for freight forwarders such as sea-land combined transport, river-sea combined transport, sea-rail combined transport, as shown in Figure 1. At present, more than 50 customers have cooperation, The company has five freight partners. Guangdong GW's international freight forwarding service covers Northeast China, North China, Central South, East China and Southwest China, and has 9 offices across the country.

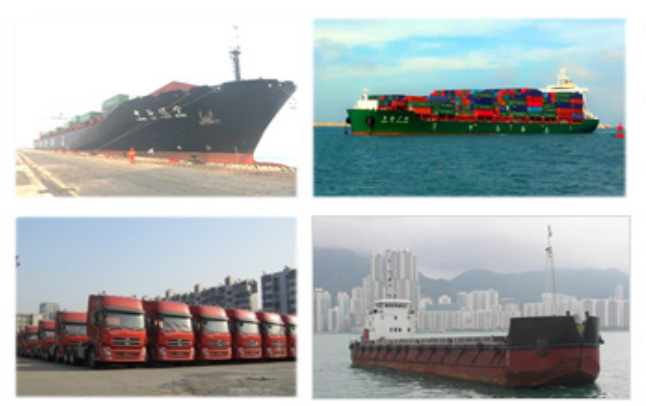

Fig 1. Main business of Guangdong GW Company Guangdong GW Company adheres to the service-oriented concept and strives to provide customers with high-quality services throughout the process. For this reason, in its daily work, Guangdong GW Company requires the customer service department, which mainly faces customers, to hold case sharing meetings 3 times a week to discuss the service quality of the customer service from receiving orders, arranging orders, tracking orders, and delivering after-sales. Each person's service work and customer feedback, from the sharing of meeting cases and active discussions among employees, find out the shortcomings and problems in the service work, and propose measures that can effectively improve the problems, so as to continuously improve the quality of service.

\section{The dilemma of Guangdong GW's customer service management}

\subsection{The professional skills of customer service are not strong}

Most of Guangdong GW's customer services are college graduates, and employees need to have certain professional knowledge and skills. At present, it is the traditional training method of masters and apprentices. Affect the work efficiency of older employees. The professional knowledge and skills of the customer service staff in the customer service department are shown in Figure 2: $20 \%$ are proficient in professional knowledge and skills, $30 \%$ are partially mastered in professional knowledge and skills, and 50\% are not mastered in professional knowledge and skills.

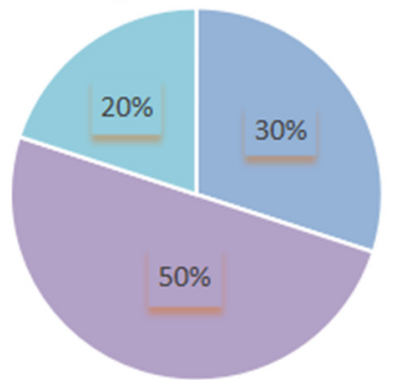

Fig 2. Statistics of professional knowledge and skill level of Guangdong GW's customer service staff. 


\subsection{RIncomplete customer service management system}

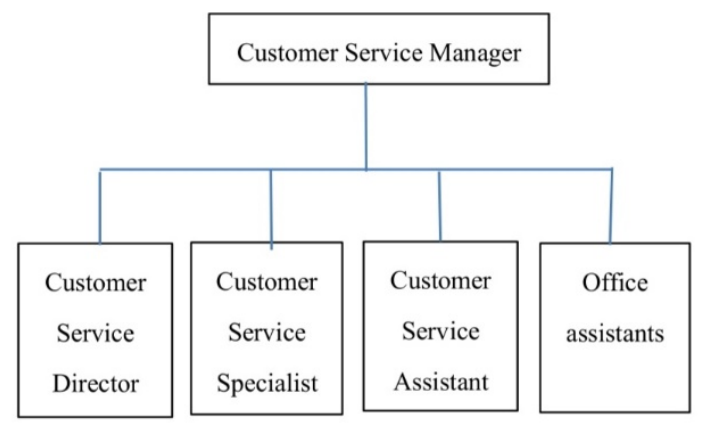

Fig 3. Organizational Structure of Customer Service Department

The organizational structure of the company's customer service department is not complete, as shown in

Figure 3. The management of the customer service

Table1. Customer Service Department KPI Table

\begin{tabular}{|c|c|c|c|c|c|}
\hline No. & KPI indicator & Assessment cycle & Weights & Source & Assessment department \\
\hline 1 & Customer opinions Timely feedback rate & \multirow{5}{*}{ per month } & $20 \%$ & \multirow{9}{*}{$\begin{array}{l}\text { Customer } \\
\text { Service } \\
\text { Department }\end{array}$} & \multirow{8}{*}{$\begin{array}{l}\text { Human Resources } \\
\text { Department }\end{array}$} \\
\hline 2 & Customer Service Information & & $10 \%$ & & \\
\hline 3 & Delivery time rate & & $10 \%$ & & \\
\hline 4 & Customer return rate & & $15 \%$ & & \\
\hline 5 & $\begin{array}{l}\text { Customer complaints } \\
\text { Resolution speed }\end{array}$ & & $10 \%$ & & \\
\hline 6 & Number of lost customers & \multirow{4}{*}{ Month/quarter/year } & $15 \%$ & & \\
\hline 7 & Number of customer return visits & & $5 \%$ & & \\
\hline 8 & customer satisfaction & & $10 \%$ & & \\
\hline 9 & Departmental collaboration satisfaction & & $5 \%$ & & Relevant departments \\
\hline
\end{tabular}

Guangdong GW has a comprehensive set of evaluation standards for customer service quality, as shown in Table 1. As shown in Table 1, Guangdong GW's customer service performance management table focuses on the completion of the company's service, ignoring the problem of profit. However, the quality of customer service needs to be centered on customer needs and adhere to the purpose of serving from the customer perspective. Blindly pursuing service, regardless of corporate profits and performance, will run counter to the purpose of customer service management.

\section{Solutions to the dilemma of Guangdong GW's customer service management}

\author{
4.1 Solutions to the low professional level of \\ customer service
}

department is the customer service manager, while the customer service director, customer service specialist and customer service assistant are ordinary employees. In actual work, managers often go on business trips, and the customer service director temporarily replaces the customer service manager, manages the entire department, and plays a leading role in other customer service specialists and assistants. This affects the relationship between colleagues in the customer service department and leads to conflicts in the management of the customer service department. The new employees do not understand whose leadership they should follow for a while, so the customer service management system is disordered.

3.3 Incomplete customer service performance management projects and insufficient incentives

Introduce excellent logistics talents and strengthen the training of staff quality. In view of the problem that employees generally have low academic qualifications and quality, it is recommended that the company develop systematic functional training for newly recruited employees. In addition to being familiar with the company's basic personnel system and basic financial processes, it should also develop corresponding business training courses for each department, Let new employees have a holistic knowledge framework for customer service work, and then gradually arrange for old employees to train practical skills and experience teaching courses. The company should introduce a group of excellent logistics talents, improve the overall cultural quality of the company's employees, and encourage and encourage employees to carry out some innovative services.

4.2 Solutions to incomplete customer service performance management projects 
Table2. Customer Service Department KPI Table

\begin{tabular}{|c|c|c|c|c|}
\hline No. & Index & Weights & Assessment criteria & $\begin{array}{r}\text { Assessment } \\
\text { department }\end{array}$ \\
\hline 1 & $\begin{array}{l}\text { Profit } \\
\text { achievement } \\
\text { rat }\end{array}$ & $25 \%$ & $\begin{array}{l}\text { 1. Get } 0 \text { points if the completion rate is below } 70 \% \\
\text { 2. } 70 \% \leq X \leq 80 \% \text { get } 5 \text { points } \\
\text { 3. } 80 \% \leq X \leq 90 \% \text { get } 10 \text { points } \\
\text { 4. } 90 \% \leq X \leq 95 \% \text { get } 15 \text { points } \\
\text { 5. } 95 \% \leq X \leq 100 \% \text { get } 20 \text { points } \\
6.25 \text { points for } 100 \% \text { or more }\end{array}$ & $\begin{array}{c}\text { Finance } \\
\text { Department }\end{array}$ \\
\hline 2 & $\begin{array}{l}\text { Target } \\
\text { completion } \\
\text { rate }\end{array}$ & $25 \%$ & $\begin{array}{l}\text { 1. Get } 0 \text { points if the completion rate is less than } 70 \% \\
\text { 2. } 70 \% \leq X \leq 80 \% \text { get } 6 \text { points } \\
\text { 3. } 80 \% \leq X \leq 90 \% \text { get } 10 \text { points } \\
\text { 4. } 90 \% \leq X \leq 95 \% \text { get } 15 \text { points } \\
\text { 5. } 95 \% \leq X \leq 100 \% \text { get } 20 \text { points } \\
\text { 6. } 25 \text { points for } 100 \% \text { or more }\end{array}$ & $\begin{array}{c}\text { Human } \\
\text { Resources } \\
\text { Department }\end{array}$ \\
\hline 3 & $\begin{array}{c}\text { On-time } \\
\text { payment rate }\end{array}$ & $20 \%$ & $\begin{array}{l}\text { 1. No score below } 70 \% \text { completion rate } \\
\text { 2. } 70 \% \leq X \leq 80 \% \text { get } 10 \text { points } \\
\text { 3. } 80 \% \leq X \leq 90 \% \text { gets } 15 \text { points } \\
\text { 4. } 90 \% \leq X \leq 100 \% \text { get } 20 \text { points }\end{array}$ & $\begin{array}{c}\text { Finance } \\
\text { Department }\end{array}$ \\
\hline 4 & $\begin{array}{c}\text { Customer } \\
\text { management }\end{array}$ & $15 \%$ & $\begin{array}{l}\text { 1. For each loss of customers below the general level, } 5 \text { points/piece, } 8 \\
\text { points/piece for important customers, and no points for VIP customers. } \\
\text { 2. Actively feedback the customer's change information, plus } 3 \\
\text { points/time, and deduct } 5 \text { points/time if you don't know or give } \\
\text { feedback in time. } \\
\text { 3. Active feedback is conducive to business development information, } \\
\text { plus } 5 \text { points/time. } \\
\text { 4. If negative profits are generated without supervision and feedback, } 5 \\
\text { points/vote will be deducted. } \\
5 \text {. If there is no original contract for the cooperative customer, } 5 \\
\text { points/piece will be deducted. } \\
\text { Cooperative business requires an order form or original reconciliation, } \\
\text { if there is no deduction of } 3 \text { points/vote. }\end{array}$ & $\begin{array}{l}\text { Human } \\
\text { Resources } \\
\text { Department }\end{array}$ \\
\hline 5 & $\begin{array}{l}\text { customer } \\
\text { satisfaction }\end{array}$ & $15 \%$ & $\begin{array}{l}\text { 1. Satisfied ( } 15 \text { points }) \text {. } \\
\text { 2. Normal ( } 8 \text { points }) \text {. } \\
\text { 3. Not satisfied ( } 0 \text { points }) \text {. }\end{array}$ & \\
\hline
\end{tabular}

Improve the customer service performance management project of the customer service department and increase the weight of customer management. The service quality and performance management mechanism of the customer service department is an important guarantee for improving the efficiency of customer service management and creating value for the company. In order to realize the scientificity and practicality of the performance management table, the performance management indicators should increase the project and weight of the customer management to complete the company's performance goals and create benefits for the company, and focus on examining the customer service staff to create benefits for the company and complete the quality of customer service services, And customer service satisfaction. Therefore, the new profit completion rate, target achievement rate, and on-time payment rate are added to the customer management table in the performance management table. The weights are $25 \%, 25 \%$ and $20 \%$ respectively, and a system of high rewards and low penalty is set correspondingly. The KPI category performance management table after the rectification is shown in Table 2 below:

\subsection{Solutions to imperfect customer service management system}

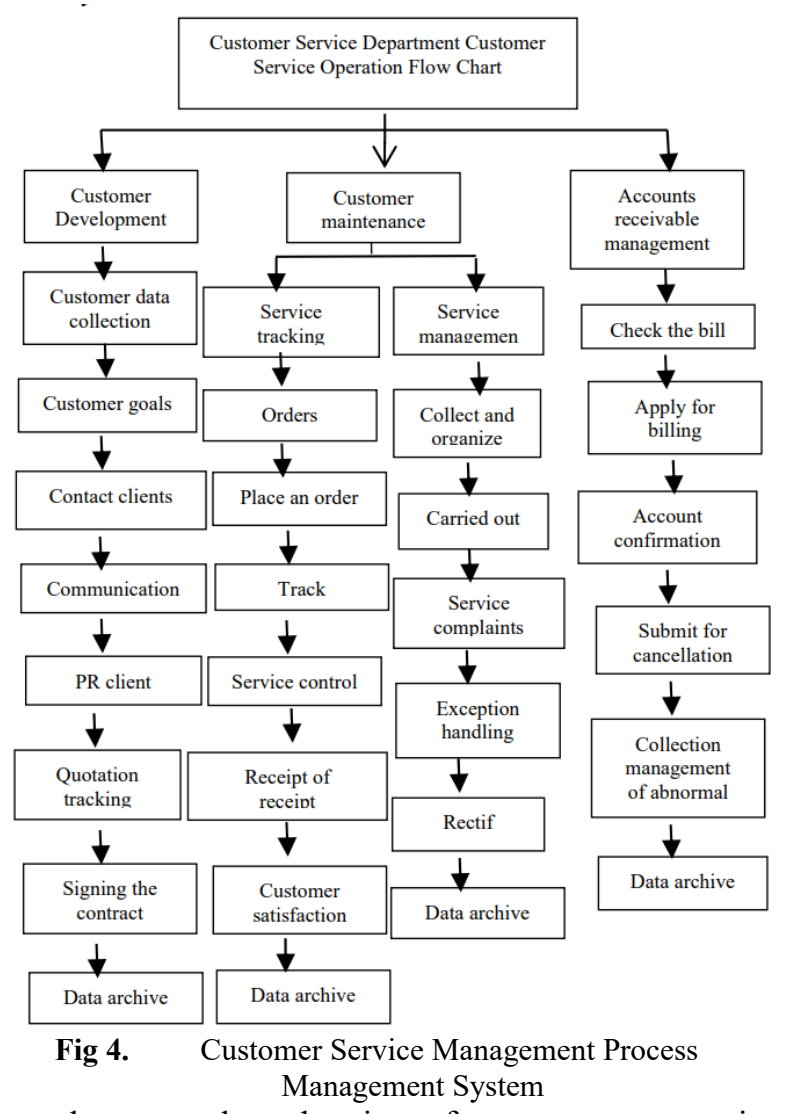

In order to solve the imperfect customer service management system, the company formulated a new customer service management process management system, and held several theoretical and operational skills 
training. After 6 months of training and actual operation, the company continued to make corrections based on the operating conditions as shown in Figure 4. Shown. It has completely changed the previous phenomenon that customers only do service, regardless of company performance and benefits. Standardized operation for customer service has played a key role and greatly improved the quality of customer service. Customer satisfaction has rapidly increased from $76 \%$ to $98 \%$.

\section{Conclusion}

In the context of the global plague, the global economy has continued to decline, and the Chinese economy has entered a new normal. The global international freight forwarding industry is becoming more and more competitive. Many small and medium-sized international freight forwarding companies are facing difficulties in survival and even in danger of bankruptcy. This article analyzes the current situation of the international freight forwarder Guangdong GW's customer service management, and the dilemma of poor customer service professional skills leading to low service quality, lack of a complete customer service management system, and imperfect customer service performance management projects. , Proposed to strengthen the training content and improvement methods for the quality of employees, introduce excellent logistics talents; optimize the performance management process, after training and effective implementation; increase the customer service to create value for the company's projects and increase the weight of assessment and other improvement measures to improve It has improved GW's own customer service level and customer service quality, and also enhanced GW's core competitiveness, and achieved better economic benefits.

This paper demonstrates and analyzes and concludes that in order to solve the dilemma of customer service management of international freight forwarders, it is necessary to improve the professional skills of customer service personnel, build a standardized landing process for customer service management, and improve the performance management of customer service to create company value. Conclusion of fruitful management innovation. It is hoped that it can be used as a reference and inspiration for other international freight forwarding companies, so as to improve the overall level of international freight forwarding service management and better serve the society.

* Corresponding author. This study is fund project: Guangdong Provincial Department of Education "Greater Bay Area Innovation and Entrepreneurship Simulation and Simulation Training Base" (Project No.2018A065164)

\section{References}

1. Q.J.Zou, "A preliminary study on the work of customer service management positions in cross- border e-commerce", Economic Research Guide, vol. 10.pp.161-181,2019.

2. Y.J.Li, "Talking about how to improve service level through customer service management", Technology Wind, vol. 04. pp.234,2019.

3. H.G.Xie, "Analysis and Design of Customer Service Management System in Customer Relationship Management-Taking the Logistics Industry as an Example”, Applied Technology and Research,vol.9. pp.58-60,2013.

4. X.Q.Wang, "Research on Customer Relationship Management Strategy of Small and Medium Supply Chain Companies_-Taking A International Logistics Company as an Example", Guangxi: Guangxi Normal University, pp. 10-21,2014.

5. J.Y.Li, "Research on the Application of Customer Relationship Management in International Freight Forwarding Companies", Value Engineering, vol. 15.pp.160-161,2014.

6. B.S.Patrick, "Burnson, FreiGWt Forwarders: Keeping it simple”, Logistics Management, 2012. 